\title{
Trajetória profissional de egressos de Curso de Mestrado Profissional em Atenção Primária à Saúde no Município de Rio de Janeiro, Brasil: estudo avaliativo
}

\author{
The professional path of postgraduates of a professional master's \\ degree in primary health care in the municipality of Rio de Janeiro, \\ Brazil: an evaluative study
}

Elyne Montenegro Engstrom (https://orcid.org/0000-0001-6149-3396) ${ }^{1}$

Virginia Alonso Hortale (https://orcid.org/0000-0002-4224-9838) ${ }^{1}$

Carlos Otávio Fiuza Moreira (https://orcid.org/0000-0001-7796-5829) ${ }^{1}$

${ }^{1}$ Escola Nacional de Saúde Pública Sérgio Arouca, Fiocruz. R. Leopoldo Bulhões 1480/9o, Manguinhos. 21041-210 Rio de Janeiro RJ Brasil. engstrom@ensp.fiocruz.br

\begin{abstract}
A four-block exploratory study was conducted with an electronic online, anonymous questionnaire to study the path of postgraduates from two professional master's degree classes, as follows: personal, current professional activity, course-professional situation relationship, and open-ended questions for positive/negative points. Results: Most of them remained in the primary care area and public services; in health care and as tutors; developed a course-related work activity, and $75 \%$ reported a high impact of the course. A lower effect was perceived in the remuneration. A higher effect was noted in the professional training, the networks of relationships, personal growth, and work. The active pedagogical strategies were well evaluated. Conclusion: This is a feasible and applicable evaluation method for graduate monitoring systems, and it allows knowing the relationship between training and work.
\end{abstract}

Key words Primary health care, Professional master's degree, Graduates, Evaluation, Health education
Resumo Visando estudar a trajetória de egressos de duas turmas de Mestrado Profissional realizouse estudo exploratório, com questionário eletrônico on line, anônimo, com quatro blocos: pessoal; atividade profissional atual; relação do curso-situação profissional e ainda perguntas abertas para pontos positivos/negativos. Resultados: a maioria mantinha-se na área da atenção primária e em serviços públicos; na assistência à saúde e muitos como preceptores; desenvolviam atividade no trabalho relacionada ao curso e $75 \%$ relatam alto o impacto do curso. Menor efeito foi percebido na remuneração e maiores na formação profissional, nas redes de relações; no crescimento pessoal e no trabalho. As estratégias pedagógicas ativas foram bem avaliadas. Conclusão: metodologia de avaliação factível e aplicável para sistemas de acompanhamento de egressos; permite conhecer a relação formação e trabalho.

Palavras-chave Atenção primária à saúde, Mestrado profissional, Egressos, Avaliação, Educação em saúde 


\section{Introdução}

No Brasil, em especial no campo da saúde, ainda é irregular a produção do conhecimento sobre a formação profissional em nível de pós-graduação para atuar no Sistema Único de Saúde (SUS) ${ }^{1,2}$. Também tem sido irregular o acompanhamento de processos de formação que discutam experiências voltadas ao desenvolvimento de novas competências profissionais ${ }^{3-5}$, embora esse acompanhamento tenha ganho mais destaque na agenda das instituições formadoras de pósgraduação, como o desenvolvimento do Plano Nacional de Pós-Graduação (PNPG) 2011-2012, criado por meio da Portaria CAPES no 106, de 17 de julho de $2012^{6}$.

Nesse sentido, estudos assistemáticos sobre o destino dos egressos de cursos de pós-graduação stricto sensu, modalidade profissional, não têm sido satisfatórios para conhecer os efeitos dessa formação na melhoria da qualidade da atenção e no fortalecimento do SUS. Tais impressões ganham força ao se constatar que a Coordenação de Aperfeiçoamento de Pessoal do Ensino Superior (Capes), órgão do Ministério da Educação responsável pela regulação e avaliação da pós-graduação stricto sensu no país, somente a partir do quadriêncio 2017 incluiu, de forma mais explícita, outras diretrizes de avaliação que transcendem aquela baseada na produção bibliométrica, especialmente de docentes, para outras que consideraram a trajetória acadêmica e profissional dos egressos dos cursos de pós-graduação. É o caso da proposta de aprimoramento do modelo de avaliação da pós-graduação, expressa em documento final da Comissão Nacional de Acompanhamento do PNPG 2011-2020, publicada em outubro de 2018, ao referir que "a avaliação contribui para melhorias continuadas e presta conta para a sociedade brasileira acerca da qualidade diferencial dos programas"6. Dessa forma, os programas de pós-graduação devem realizar seus planejamentos estratégicos, a autoavaliação dos programas, assim como o acompanhamento da trajetória de egressos como próxis do impacto dos cursos para as instituições e a sociedade. Tal atividade é especialmente relevante nos cursos de modalidade profissional, nos quais espera-se que a produção de conhecimento esteja relacionada às demandas institucionais e a serviço da sociedade e do Estado; os produtos da formação devem ser aplicados, para poderem ser transformadores da realidade, com o desenvolvimento de novas formas de translação do conhecimento. Para tal, é preciso que o processo de formação desenvolva nos alunos, por meio de aquisição de competências para a produção de conhecimento em sua área específica, o pensamento crítico, a autonomia, a capacidade de geração e a transferência de tecnologias e de conhecimentos inovadores para soluções de problemas em seu campo de atuação. É preciso ainda que os currículos permitam uma formação mais flexível, dialógica às demandas. Acreditando ser esta a missão da formação profissional, desenvolveu-se experiência de curso de mestrado profissional em Atenção Primária à Saúde, seguida de estudo avaliativo, em que a metodologia e os resultados são apresentados neste artigo.

No que se refere especificamente à temática abordada no referido curso, a Atenção Primária à Saúde (APS) foi introduzida na Declaração de Alma-Ata, em 1978, e consolidada no Brasil nas décadas seguintes por sucessivas recomendações internacionais e nacionais. É considerada a base para um novo modelo de atenção em sistemas públicos e universais de saúde que tenham como foco o usuário-cidadão, a família e a comunidade, ancorando-se em atributos essenciais: porta de entrada principal, vínculo longitudinal, integralidade e coordenação do cuidado ${ }^{7,8}$. Ao longo dos últimos vinte anos, diversas normativas do governo federal têm induzido a reorganização do modelo de APS, movimentos que se consolidaram com a Política Nacional de Atenção Básica (PNAB), publicada em 2006, com reedições em 2011 e 2017, normativas que reafirmaram a opção prioritária pela Estratégia Saúde da Família, integrada à Rede de Atenção à Saúde no país ${ }^{8,9}$. Apesar da considerável expansão da Saúde da Família no Brasil, especialmente em centros urbanos, a cobertura ainda é heterogênea nas diversas regiões do país, com muitos desafios para a melhoria da qualidade da atenção prestada, com modelos para uma atenção integral, robusta e efetiva $^{10}$.

Não foi obra do acaso que importantes discussões sobre a formação em saúde tenham emergido junto à questão da reorganização do sistema de atenção; já era, então, relativamente clara, a inadequação dos perfis profissionais para um novo processo de trabalho em saúde. Nesse sentido, foram estabelecidas as Diretrizes Curriculares Nacionais para os cursos da saúde no início dos anos 2000, relacionadas de forma explícita a mudanças do modelo de atenção. A partir daí, a formação em saúde deixou de ser um tema marginal nas esferas governamentais nacionais ${ }^{11}$. Nessa mesma época, o Ministério da Saúde no Brasil passou a fomentar os Mestrados 
Profissionais, voltados para profissionais que já atuavam nos serviços de saúde. Essa modalidade de curso stricto sensu é reconhecido pela Capes desde $1998^{1}$.

Hoje é praticamente consenso na comunidade de estudiosos da educação que a aprendizagem extrapola os limites da educação formal inicial, devendo ser estimulada ao longo da vida profissional. $\mathrm{Na}$ área da saúde, os conhecimentos e as práticas são constantemente reavaliados e transformados. Para Lima ${ }^{12}$, a reflexão sobre as práticas profissionais deve se dar em uma construção dialogada "entre os mundos da escola e do trabalho com a sociedade a partir da explicitação de diferentes interesses, valores e saberes, social e historicamente constituídos. Os currículos orientados por esta abordagem são desenvolvidos em torno de eixos que articulam e integram: teoria e prática; capacidades e ações; contextos; e critérios de excelência".

No que se refere à questão do acompanhamento de egressos, a Fundação Oswaldo Cruz (Fiocruz) - órgão do Ministério da Saúde e instituição de ciência e tecnologia dedicada à pesquisa, ao ensino e ao desenvolvimento tecnológico no campo da saúde, e que ocupa posição destacada na formação profissional e na formulação de diretrizes para o desenvolvimento científico e tecnológico no campo da saúde - já empreendeu alguns esforços no mapeamento da trajetória de seus egressos ${ }^{13,14}$.

Essas pesquisas inspiraram e foram aprofundadas com o presente estudo. Com o objetivo de estudar a trajetória de egressos de um curso de mestrado profissional, procurou-se captar suas visões em relação às contribuições desta formação para o mundo do trabalho, uma análise dos sucessos e das limitações, de forma a contribuir para o desenvolvimento de processos de acompanhamento de cursos de pós-graduação.

\section{O curso}

Considerando a importância da APS e, mais especificamente, a Estratégia Saúde da Família (ESF) como modelo de atenção na formulação de políticas públicas de saúde no Brasil, ainda persistem inúmeros desafios voltados a ampliar a oferta e dar maior qualidade às práticas nos serviços de saúde em grandes centros urbanos ${ }^{10}$.

Esses desafios estão presentes no Município do Rio de Janeiro (MRJ), locus do presente estudo. Desde 2009, os gestores municipais da saúde imprimiram uma reforma no modelo de atenção e de gestão da APS na cidade, que resultou no aumento de cobertura da ESF de 5\% para cerca de $70 \%$, respectivamente entre o período de 2009 a $2016^{15}$. Tal ampliação dos serviços básicos ofertados foi avaliada em estudos locais em que se identificou a necessidade de melhoria da qualidade de alguns atributos, como a coordenação do cuidado, para além da ampliação do acesso ${ }^{15,16}$.

Nesse mesmo contexto, destacam-se ainda os investimentos municipais em processos de formação em saúde, com a criação de um grande Programa de Residência Médica em Medicina de Família e Comunidade e o apoio à Residência Multiprofissional, além da Residência em Enfermagem na Atenção Básica - formações que exigiam a presença de preceptores habilitados nos serviços, uma das competências esperadas pelo curso de MPAPS ${ }^{17,18}$.

Como parte desse processo e visando contribuir para a melhoria da formação profissional, em 2010 foi proposto o Curso de MPAPS com ênfase na ESF, fruto de uma parceria entre a Escola Nacional de Saúde Pública Sérgio Arouca da Fiocruz e a Secretaria Municipal de Saúde (SMS) do Rio de Janeiro. O currículo do curso foi inspirado no Mestrado Profissional em Saúde da Família da Rede Nordeste de Formação em Saúde da Família (RENASF), uma parceria entre universidades daquela região e a Fiocruz, e tendo como referência a prática de profissionais de saúde que atuam na APS ${ }^{14,19}$, com adaptações à realidade epidemiológica e assistencial do Município do Rio de Janeiro.

Coerente com as diretrizes gerais dos Mestrados Profissionais, o curso teve por objetivo sistematizar o conhecimento técnico-científico produzido no cotidiano de atuação dos profissionais, visando à ampliação de competências para melhorar a qualidade do trabalho na APS e contribuir para o fortalecimento do SUS. As temáticas que compuseram o currículo relacionavam-se aos conhecimentos, habilidades e atitudes necessários ao alcance das competências esperadas para os profissionais da APS. O currrículo, compreendido como construção social, contemplava, além dos conteúdos, o processo de ensino-aprendizagem e a avaliação, a partir de intencionalidade explícita do perfil de competência do egresso: lideranças profissionais aptas a atuar de forma reflexiva em atividades de investigação e de ensino em serviço (preceptoria), sem afastarem-se de suas atividades na atenção ou gestão da ESF. Para tal intencionalidade, a estrutura curricular correspondia a sete módulos temáticos relacionados às grandes áreas de competência esperadas: i) desenvolver ações na promoção da saúde, 
ii) compreender e atuar no modelo de atenção primária integral e iii) ter competência para atuar na gestão da clínica, iv) utilizar informações e comunicação em saúde, v) atuar no planejamento e avaliação em saúde, vi) realizar atividades de educação em saúde, em especial na preceptoria e no exercício das metodologias de ensino e aprendizagem, e vii) produzir conhecimentos científicos e/ou tecnológico, adotando-se metodologias de investigação científica. Para atender ao processo de desenvolvimento dos produtos do curso (dissertação, material técnico, projetos de intervenção, dentre outros) foi proposto o módulo "Seminários de Acompanhamento" e uma seção variável, cujo conteúdo foi desenvolvido a partir dos interesses dos alunos e gestores, denominada "Tópicos Especiais". O curso teve carga horária total de 1470 horas, com $80 \%$ em atividades presenciais semanais ${ }^{18}$.

Para alcançar os objetivos de aprendizagem foram utilizadas diversas estratégias educacionais com base nas metodologias ativas, considerandose a adequação da estratégia para atingir a competência esperada e sua respectiva forma de avaliação, que era realizada de forma sistemática. No
Quadro 1, destacam-se as principais estratégias adotadas, como grupo tutorial, exposição dialogada, seminário, estudo dirigido, treinamento de habilidade, projetos em equipe, dentre outras.

A proposta do curso foi sistematizada e entregue aos alunos na forma de um caderno impresso, que incluía as orientações para o curso ${ }^{20}$. Desenvolveu-se também uma comunidade virtual de aprendizagem para realização de algumas atividades em forma de educação a distância (EAD), acompanhadas pela coordenação do curso.

Foram ofertadas duas turmas, nos anos de 2011-2013 e 2013-2015, com 24 vagas por turma. Embora de composição multiprofissional, cerca de metade dos alunos aprovados no processo seletivo eram médicos. Como pré-requisito da inscrição, todos os candidatos deveriam trabalhar na Atenção Básica do governo municipal, quer fossem profissionais da assistência ou gerentes de unidades básicas de saúde. Do universo de matriculados no curso, foram titulados $90 \%$ e $85 \%$, respectivamente na $1^{\mathrm{a}}$ e $2^{\mathrm{a}}$ turma. Cabe destacar que os autores deste estudo atuaram na elaboração do currículo, na coordenação e na docência das duas turmas do curso.

Quadro 1. Descrição das estratégias educacionais e dos instrumentos de avaliação dos conteúdos dos diversos Módulos do curso.

\begin{tabular}{|l|l|}
\hline \multicolumn{1}{|c|}{ Estratégia educacional } & \multicolumn{1}{|c|}{ Instrumento de avaliação dos conteúdos } \\
\hline Grupo Tutorial & $\begin{array}{l}\text { Processamento de situações-problema, casos ou relato de práticas em forma } \\
\text { de narrativas que abordam diferentes temas, como base na Aprendizagem } \\
\text { Baseada em Problema (ABP). }\end{array}$ \\
\hline Seminário & $\begin{array}{l}\text { Atividade educacional realizada necessariamente por uma equipe ou grupo e } \\
\text { com a participação efetiva de todos os seus membros, com tema e planejamento } \\
\text { prévio. }\end{array}$ \\
\hline $\begin{array}{l}\text { Aprendizagem baseada em } \\
\text { equipe }\end{array}$ & $\begin{array}{l}\text { Promover a construção do conhecimento, com ênfase na aplicação, e a } \\
\text { aprendizagem colaborativa. A partir de um texto, há perguntas, com resposta } \\
\text { individual e coletiva. }\end{array}$ \\
\hline $\begin{array}{l}\text { Narrativas baseadas em Prática } \\
\text { na comunidade }\end{array}$ & $\begin{array}{l}\text { Escolha de tema específico para produção de relato ou narrativa da situação } \\
\text { cotidiana vivenciada. Análise segundo espiral construtivista. }\end{array}$ \\
\hline Desenvolvimneto de habilidades & Desenvolvimento de habilidades cognitivas, motoras. \\
\hline Projeto em equipe & $\begin{array}{l}\text { Estratégia para exercitar a elaboração de projetos de intervenção por uma } \\
\text { equipe }\end{array}$ \\
\hline Mini-Exposição & $\begin{array}{l}\text { A exposição é feita para toda a turma, tendo o diálogo com os alunos como } \\
\text { recurso fundamental. }\end{array}$ \\
\hline Estudo dirigido & $\begin{array}{l}\text { Estratégia de estudo individual orientado, para habilidade de ler, interpretar } \\
\text { e escrever sobre determinado tema. }\end{array}$ \\
\hline $\begin{array}{l}\text { Simulação, Dramatização, } \\
\text { Vivências }\end{array}$ & $\begin{array}{l}\text { Utilizada para representar de forma crítica o exercício de práticas } \\
\text { profissionais no contexto da APS, atividade em grupo, com roteiro } \\
\text { estabelecido. }\end{array}$ \\
\hline Comunidade Virtual & Realização de Fóruns, atividades em equipes. \\
\hline Fonte: elaboração própria. & \\
\hline
\end{tabular}




\section{Metodologia}

Trata-se de estudo exploratório, seccional, com levantamento de dados quantitativos e qualitativos acerca das relações entre a formação no MPAPS e o trabalho em saúde dos egressos do referido curso. Embora o termo egresso possa ser utilizado para referir-se ao aluno formado ou abranger os alunos que saíram do curso por abandono, transferência ou jubilamento, sem adentrar no mérito deste aspecto, para a realização do presente estudo, consideramos como egresso apenas o aluno que concluiu seus estudos no curso.

O universo do estudo foram 42 egressos, identificados por meio do Serviço de Gerenciamento Acadêmico de Alunos (SIGA) da ENSP. Como instrumento de coleta de dados, elaborou-se um questionário eletrônico para preenchimento on line, cujo link foi enviado por correio eletrônico a todos os participantes e que ficou disponível entre os meses de julho e agosto de 2016. Os respondentes não foram identificados. A escolha do procedimento on line justificou-se por sua acessibilidade e otimização do tempo dos respondentes. Para minimizar possíveis perdas, a equipe da pesquisa fez contato prévio com todos os participantes, por correio eletrônico ou telefone, sensibilizando-os sobre a importância do estudo, atualizando endereços eletrônicos e lembrando prazos. Para esclarecimento de dúvidas e contato com a equipe da investigação ficou disponível um endereço eletrônico específico.

O questionário foi composto por quatro blocos: i) dados cadastrais; ii) natureza da atividade profissional atual; iii) relação do curso com a situação profissional atual; iv) avaliação do curso. Como parte deste último bloco, havia campos para comentários sobre se o atual processo de trabalho do egresso foi facilitado ou limitado pelos aspectos do curso relacionados no questionário, a saber: processo seletivo, conjunto dos módulos, conteúdos abordados, corpo docente, práticas pedagógicas adotadas, oportunidade de trabalho em pequenos grupos, aprendizagem de trabalho em equipe, utilização de situações-problema e oportunidades de problematização, desenvolvimento de habilidades de comunicação, desenvolvimento do seu potencial de liderança, estratégias de avaliação de alunos, estratégias de avaliação de docentes e de módulos pelos alunos, aprendizagem de métodos e técnicas de pesquisa, orientação da dissertação, estímulo à busca ativa de dados em bases eletrônicas, serviços prestados pela secretaria acadêmica, relação da coordenação com os alunos, instalações, serviços e acervo da biblio- teca, infraestrutura para aulas e para reuniões de grupo. Ao final, dispunha-se ainda de espaço aberto para que o egresso opinasse sobre pontos fortes e fracos da formação para o exercício profissional.

Realizou-se teste-piloto com profissional que não foi incluído no estudo, com o objetivo de verificar a inteligibilidade do instrumento, pertinência dos enunciados, confiabilidade das respostas, além do controle de possíveis vieses decorrentes do seu preenchimento.

As respostas cujas perguntas tinham campos fechados foram consolidadas em planilha Excel com análise das frequências simples. As respostas cujas perguntas eram abertas foram transcritas e sistematizadas de forma qualitativa, por categorias temáticas de conteúdo, segundo Flick ${ }^{21}$, que exploraram aspectos referentes aos sucessos e limitações da formação para o mundo do trabalho. Visando isolar, na medida do possível, variáveis intervenientes, empregou-se a estratégia de controle reflexivo (reflexive controls), na qual "sujeitos que recebem a intervenção são comparados consigo mesmos, quando perguntamos sobre o trabalho antes e depois da intervenção, no caso, o curso"22. Esta opção foi necessária em decorrência do tempo relativamente curto entre a conclusão dos cursos e a coleta de dados. No caso de estudo de trajetória de egressos, é importante que haja um certo intervalo de tempo, o qual consideramos plausível em torno de cinco anos, para se captar os efeitos da formação na vida profissional. O projeto obteve aprovação do Comitê de Ética em Pesquisa da ENSP. A concordância na participação implicou em acessar o link informado na mensagem enviada por e-mail, entrar na primeira tela do questionário e visualizar o Termo de Consentimento Livre e Esclarecido (TCLE) e, em seguida, acessar as demais telas do questionário.

\section{Resultados e discussão}

\section{Perfil e natureza da atividade profissional atual dos egressos}

Do universo de egressos, 22 preencheram o questionário, o que significa um percentual de resposta de $53 \%$. O fato de 17 respondentes serem do sexo feminino e 5 do sexo masculino corrobora achados de estudos sobre a feminização da área da saúde pública ${ }^{23}$.

Quanto à categoria profissional dos respondentes, $55,5 \%$ eram médicos, $28 \%$ enfermeiros, sendo os demais das áreas de odontologia, far- 
mácia e nutrição, perfil semelhante ao universo dos alunos matriculados. A grande maioria dos respondentes (>90\%) referiram ter um ou mais cursos de especialização antes da entrada no mestrado, o que pode significar uma tendência de acumulação do capital cultural em sua forma institucionalizada, o diploma, conforme os estudos de sociologia da educação de Bourdieu ${ }^{24,25}$.

A Tabela 1 apresenta aspectos relacionados à inserção profissional dos egressos à época da coleta de dados e havia a possibilidade de múltiplas respostas em algumas questões, que o egresso lis- tasse um ou vários locais de atuação profissional (característicos de profissionais da saúde), o que justifica o número de respostas maior do que de participantes. Evidenciou-se que 17 respondentes permaneciam atuando no âmbito municipal, e apenas quatro deles migraram para outras esferas públicas, um para nível federal e um estadual do SUS e dois para instituição de ensino e pesquisa (Ministério da Educação).

Elevada e equivalente proporção deles permaneceu atuando na Atenção Primária à Saúde (82\%); apenas $9 \%$ passaram a atuar na atenção

Tabela 1. Distribuição de variáveis relacionadas à Inserção Profissional dos Egressos. Município do Rio de Janeiro, 2016.

\begin{tabular}{|c|c|c|}
\hline Variáveis: Inserção em Julho/agosto de 2016 & n & $\%$ \\
\hline \multicolumn{3}{|c|}{$\begin{array}{l}\text { Tipo de Instituição em que trabalha }(\mathrm{n}=24 \text { respostas). Possível marcar } \\
\text { mais de uma resposta }\end{array}$} \\
\hline Rede da Secretaria Municipal de Saúde & 17 & 77,3 \\
\hline Rede da Secretaria Estadual de Saúde & 2 & 9,1 \\
\hline Rede do Ministério da Saúde & 3 & 13,6 \\
\hline Outro & 2 & 9,1 \\
\hline \multicolumn{3}{|l|}{$\begin{array}{l}\text { Nível de atenção: principal inserção profissional } \\
(\mathrm{n}=23 \text { respostas ). Possível marcar mais de uma resposta }\end{array}$} \\
\hline Atenção Primária à Saúde & 18 & 81,8 \\
\hline Atenção Especializada/Ambulatório & 2 & 9,1 \\
\hline Hospital & 0 & 0,0 \\
\hline Outro & 3 & 13,6 \\
\hline \multicolumn{3}{|c|}{ Tipo de Atividade ( $\mathrm{n}=51$ respostas) Possível marcar mais de uma resposta } \\
\hline Assistência à saúde & 12 & 54,6 \\
\hline Preceptoria em Serviço & 11 & 50,0 \\
\hline Gestão em saúde & 12 & 54,2 \\
\hline Consultoria & 1 & 4,6 \\
\hline Ensino & 10 & 45,5 \\
\hline Pesquisa & 5 & 22,7 \\
\hline Outro & 0 & 0,0 \\
\hline \multicolumn{3}{|l|}{$\begin{array}{l}\text { Natureza da instituição que trabalha }(\mathrm{n}=22) \text {. Apenas uma resposta } \\
\text { (principal instituição, maior carga horária) }\end{array}$} \\
\hline Pública & 20 & 90,0 \\
\hline Privada & 0 & 0,0 \\
\hline Outro & 2 & 9,1 \\
\hline \multicolumn{3}{|c|}{$\begin{array}{l}\text { Tipo de vínculo }(\mathrm{n}=22) \text { Apenas uma resposta (principal instituição, maior } \\
\text { carga horária) }\end{array}$} \\
\hline Regime Jurídico Único & 6 & 27,3 \\
\hline Contrato CLT & 12 & 54,6 \\
\hline Cooperativado & 0 & 0,0 \\
\hline Contrato temporário & 0 & 0,0 \\
\hline Autônomo & 0 & 0,0 \\
\hline Bolsista & 0 & 0,0 \\
\hline Outro & 4 & 18,2 \\
\hline
\end{tabular}

Fonte: elaboração própria. 
especializada ou ambulatório e nenhum se deslocou para a atenção hospitalar; dois respondentes não trabalham em qualquer desses níveis do sistema de saúde, tendo migrado conforme já citado anteriormente, para a área de educação.

Mais da metade dos respondentes trabalhava diretamente na assistência à saúde e a maioria destes acumulava ainda a função de preceptoria. $\mathrm{O}$ desenvolvimento de atividades de ensino e pesquisa foi citado por $45,5 \%$ e $22,7 \%$ deles, respectivamente, evidenciando a atividade de produção de conhecimento nos serviços de saúde. Esses dados se assemelham a estudo de Gomes e Goldemberg ${ }^{23}$, em que "70\% dos egressos do MP desenvolvem atividades de gestão em saúde, além de atividades de pesquisa (30\%), acompanhadas de ensino (23,3\%), de desenvolvimento tecnológico e de assistência e consultoria (20\%)". O relato de que a metade dos respondentes passou a atuar na gestão em saúde expressaria um efeito do protagonismo do egresso no cenário municipal, considerando que a formação de lideranças com visão crítica para a tomada de decisão era uma das competências esperadas e estimuladas no curso.

Apesar de a grande maioria atuar em serviços públicos ligados ao SUS (90\%) e nenhum na iniciativa privada, havia diversidade quanto aos vínculos trabalhistas: mais da metade era contratada como celetista - pelas leis trabalhistas (55\%) e $27 \%$ eram servidores públicos, perfil de vínculo que demonstra a opção da gestão municipal do Rio de Janeiro, a partir de 2009, por contratos celetistas geridos pelas Organizações Sociais em Saúde (OSS).

\section{Relações entre o trabalho atual e a formação no MPAPS}

Apenas $13,6 \%$ referiu manter a mesma atividade profissional, na mesma instituição (ou seja, na SMS). Para os demais, houve mudança na natureza da atividade profissional, sendo que destes, $40,9 \%$ mudaram de atividades mas permaneceram na SMS e $31,8 \%$ mudaram também de instituição (migraram para universidades, ministério da saúde ou secretaria estadual). Contudo, mais de $80 \%$ dos respondentes desenvolviam atividades no trabalho relacionadas ao curso. Sobre os efeitos do curso no trabalho atual, 77,3\% consideram alto, $18 \%$ médio e apenas $4,5 \%$ consideraram baixo o impacto do curso (Tabela 2).

Em relação às mudanças atribuídas à formação, houve incremento nos aspectos da remuneração financeira dos egressos, das relações do trabalho, da relevância social do mesmo, do prestígio, das oportunidades de desenvolvimento profissional e de novas aprendizagens, com criatividade e autonomia (Figura 1).

Esses achados estão em sintonia a outro estudo com egressos de três cursos de mestrado profissional na área de gestão de ciência e tecnologia em saúde, embora este último também tenha constatado que o acúmulo de conhecimentos gerado não contribuiu para a implementação da proposta de trabalhos de pesquisa dos egressos, indicando um baixo compromisso institucional com a recepção e a implementação dos mesmos ${ }^{13}$.

Outros aspectos a ressaltar fotam o stress e a carga de trabalho percebidos pelos egressos; estas foram dimensões que obtiveram menor percepção de melhoria em relação ao período anterior ao curso. Doença relacionada ao esgotamento e stress no trabalho, a Síndrome de Burnout é composta por três dimensões específicas, exaustão emocional, despersonalização e realização profissional. Acomete principalmente trabalhadores que atuam com serviços humanos, dando respostas às necessidades das pessoas, como no caso

Tabela 2. Distribuição de variáveis segundo características do trabalho do egresso em julho/agosto de 2016 e a formação no curso. Município do Rio de Janeiro, 2016.

\begin{tabular}{|c|c|c|}
\hline Variáveis & n $(=22)$ & $\%$ \\
\hline \multicolumn{3}{|c|}{ No início do mestrado principal atividade profissional } \\
\hline $\begin{array}{l}\text { A mesma da atividade profissional } \\
\text { atual na mesma instituição }\end{array}$ & 3 & 13,6 \\
\hline $\begin{array}{l}\text { A mesma da atividade profissional } \\
\text { atual em outra instituição }\end{array}$ & 3 & 13,6 \\
\hline $\begin{array}{l}\text { Diferente da atividade profissional } \\
\text { atual na mesma instituição }\end{array}$ & 9 & 40,9 \\
\hline $\begin{array}{l}\text { Diferente da atividade profissional } \\
\text { atual em outra instituição }\end{array}$ & 7 & 31,8 \\
\hline \multicolumn{3}{|c|}{$\begin{array}{l}\text { O quanto a principal atividade profissional está } \\
\text { relacionada ao curso de mestrado }\end{array}$} \\
\hline Muito relacionada & 15 & 68,2 \\
\hline Razoavelmente relacionada & 4 & 18,2 \\
\hline Pouco relacionada & 3 & 13,6 \\
\hline Não tem relação & 0 & 0,0 \\
\hline \multicolumn{3}{|c|}{$\begin{array}{l}\text { Impacto do mestrado na sua vida profissional (apenas } \\
\text { uma opção assinalada): }\end{array}$} \\
\hline Alto & 17 & 77,3 \\
\hline Médio & 4 & 18,3 \\
\hline Baixo & 1 & 4,6 \\
\hline
\end{tabular}

Fonte: elaboração própria. 


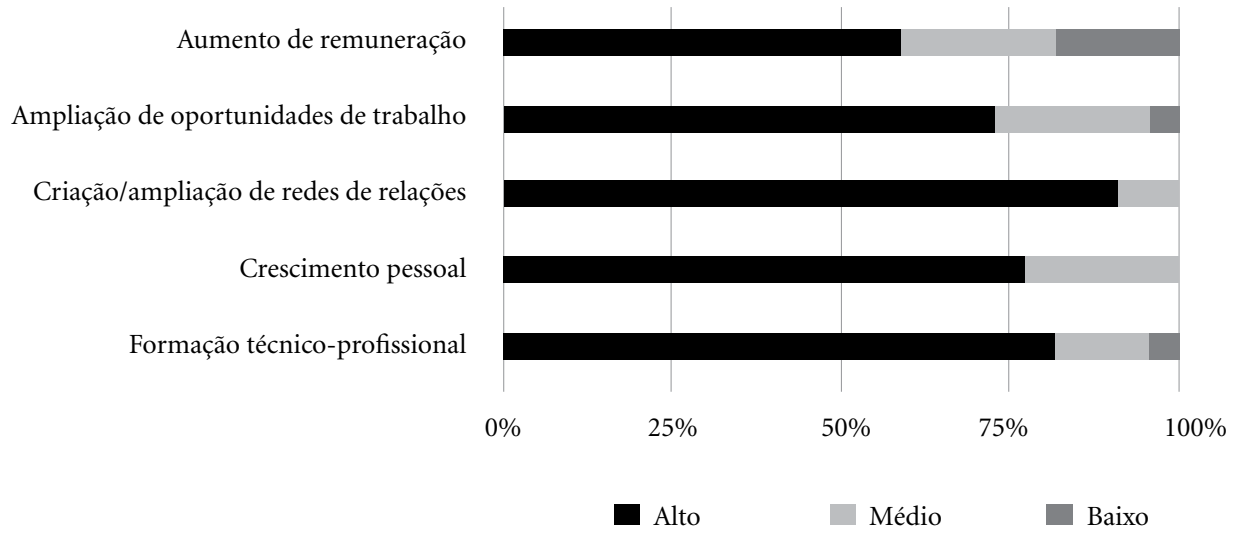

Figura 1. Proporção (\%) do grau de impacto do Curso de Mestrado em gradientes (alto, médio, baixo) relativos ao trabalho dos egressos. Município do Rio de Janeiro, 2017.

Fonte: elaboração própria.

das unidades básicas de saúde ${ }^{26-28}$. Corroborando nossos achados, estudo seccional realizado com gerentes das unidades básicas de saúde do $\mathrm{Mu}$ nicípio do Rio de Janeiro, em 2015, evidenciou que grande parte dos gestores de APS apresentam níveis altos ou moderados nas três dimensões do Burnout e a avaliação global da Síndrome foi identificada em $11,2 \%$ dos gerentes, percentual maior do que encontrado em estudos nacionais com profissionais da Atenção Básica à Saúde ${ }^{29}$. Estudo realizado com profissionais de saúde da atenção básica do município de Juiz de Fora/MG evidenciou que a prevalência da síndrome foi de $51 \%$, destacando-se que ela foi maior entre os profissionais de enfermagem, o que leva a pensar na complexidade e exigência do trabalho nos serviços de atenção básica de saúde ${ }^{30}$.

\section{Avaliação do curso pelo egresso}

No que se refere à organização do curso, as opiniões dos egressos foram excelente/boa para a grande maioria (>90\%) nos aspectos de seleção, conteúdos, corpo docente e, principalmente, em relação às estratégias educacionais relacionadas às metodologias ativas, com destaque para os trabalhos nos grupos tutoriais (situações-proble$\mathrm{ma})$, assim como em relação ao espaço físico. Aspectos de desempenho incipiente (em torno de $30-40 \%)$ referiram-se às estratégias de avaliação de docentes e de módulos pelos alunos e ainda à aprendizagem de métodos e técnicas de pesquisa (Tabela 3).

\section{Opinião dos egressos sobre a formação}

Em relação às questões abertas, quando os egressos expressaram suas opiniões em texto livre, os comentários foram em sua maioria positivos (sucessos) e versaram sobre os conteúdos do curso, a metodologia educacional, a coordenação, os docentes e os orientadores. Os comentários negativos (limitantes) versaram sobre a estratégia de avaliação, "não cumprida em sua totalidade", e sobre metodologia de pesquisa, apresentada de "forma superficial".

As opiniões positivas eram em maior número e foram agrupadas em duas subcategorias para fins de apresentação neste artigo: processo de ensino-aprendizagem e coordenação.

Em relação ao processo de ensino-aprendizagem, os comentários positivos se detiveram nas metodologias ativas e sua importância para o desenvolvimento de habilidades da fala e da comunicação, de atividades em pequenos grupos, de abordagem de situações-problema, do pensamento crítico, da reflexão sobre a prática em serviço. Tais assertivas reforçaram opção pedagógica do curso de Mestrado Profissional que procurou estabelecer uma relação clara entre processos de formação e atuação nos serviços de saúde, entre educação ou formação e trabalho em saúde e, de modo específico, entre as estratégias educacionais escolhidas e os desempenhos (individual e coletivo) dos alunos. Os desenhos curriculares e as estratégias educacionais que podem ser empregadas são múltiplos e produzirão sentidos e 
Tabela 3. Avaliação de aspectos da estrutura curricular do curso na opinião dos egressos $(n=22)$. Município do Rio de Janeiro, 2016.

\begin{tabular}{|c|c|c|c|c|c|}
\hline Variáveis & $\begin{array}{c}\text { Excelente/ } \\
\text { Bom } \\
\%\end{array}$ & $\begin{array}{c}\text { Razoável } \\
\%\end{array}$ & $\begin{array}{c}\text { Fraco/ } \\
\text { Muito Fraco } \\
\%\end{array}$ & $\begin{array}{c}\text { Não } \\
\text { opinou } \\
\%\end{array}$ & Total \\
\hline Seleção & 90,9 & 9,1 & 0,0 & 0,0 & 100,0 \\
\hline Disciplinas ou Módulos & 95,5 & 4,5 & 0,0 & 0,0 & 100,0 \\
\hline Conteúdos & 86,4 & 9,1 & 4,5 & 0,0 & 100,0 \\
\hline Corpo docente & 95,4 & 4,6 & 0,0 & 0,0 & 100,0 \\
\hline Práticas pedagógicas & 90,9 & 9,1 & 0,0 & 0,0 & 100,0 \\
\hline Trabalho Grupos & 100,0 & 0,0 & 0,0 & 0,0 & 100,0 \\
\hline Trabalho em equipe & 86,4 & 9,1 & 0,0 & 4,5 & 100,0 \\
\hline Situações-problema e problematização & 90,9 & 4,5 & 0,0 & 4,6 & 100,0 \\
\hline Habilidades de comunicação & 90,9 & 9,1 & 0,0 & 0,0 & 100,0 \\
\hline Liderança & 77,3 & 18,2 & 4,5 & 0,0 & 100,0 \\
\hline Avaliação de alunos & 86,4 & 9,0 & 4,6 & 0,0 & 100,0 \\
\hline Avaliação docentes e módulos por alunos & 59,1 & 27,3 & 9,0 & 4,6 & 100,0 \\
\hline Aprendizagem de métodos de pesquisa & 68,2 & 27,2 & 4,6 & 0,0 & 100,0 \\
\hline Orientação da dissertação & 81,8 & 18,2 & 0,0 & 0,0 & 100,0 \\
\hline Busca de dados em bases eletrônicas & 81,8 & 13,6 & 4,6 & 0,0 & 100,0 \\
\hline Serviços da Secretaria Acadêmica & 77,3 & 13,5 & 4,6 & 4,6 & 100,0 \\
\hline Relação com a Coordenação & 100,0 & 0,0 & 0,0 & 0,0 & 100,0 \\
\hline Instalações, serviços e biblioteca & 95,5 & 0,0 & 0,0 & 4,5 & 100,0 \\
\hline Infraestrutura - aulas & 100,0 & 0,0 & 0,0 & 0,0 & 100,0 \\
\hline Infraestrutura reuniões de grupo & 100,0 & 0,0 & 0,0 & 0,0 & 100,0 \\
\hline
\end{tabular}

efeitos muito distintos sobre as práticas, de acordo com o método empregado ${ }^{31}$.

Três opiniões expressam bem a importância de como essas metodologias influenciaram o processo de trabalho dos egressos na Atenção Primária à Saúde e na preceptoria:

O que mais impacta no processo de trabalho foi utilização de situações-problema e oportunidades de problematização no mestrado. Essa oportunidade influenciou no diálogo com os meus colegas e na vivência de experiências do município do Rio de Janeiro.

Sem dúvida, o que mais chamou a atenção foi travar o contato com metodologias ativas e colocá - las em prática. Isso até hoje norteia minha prática docente e qualifica ainda mais a residência de onde sou preceptor.

A aprendizagem fez com que ampliasse a visão do processo de trabalho e facilitou a utilização de ferramentas em prol da qualidade, como também abriu outras oportunidades de trabalho.

Tais estratégias metodológicas (ativas) de ensino-aprendizagem tem sido utilizadas desde 2011 em experiências na pós-graduação stricto sensu, em mestrados profissionais. Lima ${ }^{32}$ apresenta uma representação gráfica denominada "espiral construtivista", onde tais estratégias se integram em movimentos de identificação de problemas, formulação de explicações e elaboração de questões de aprendizagem, a busca por novas informações, visando a construção de novos significados e a avaliação de processos e produtos para uma "nova síntese".

Quanto à coordenação, incluído os docentes, os comentários detiveram-se nos aspectos relativos à disponibilidade deles. Destacam-se dois comentários positivos:

Tanto a relação com a coordenação do curso como com os orientadores foram fundamentais para o melhor aproveitamento do curso e da elaboração da dissertação.

Um corpo docente flexivel, proativo e extremamente acessivel permitem uma melhor experiência no aprendizado.

Para finalizar, um comentário pode ser considerado a síntese dos comentários positivos dos alunos sobre a importância do Curso na formação deles: 
O conteúdo, o corpo docente, a estruturação do curso e o meu orientador me subsidiaram a alcançar projetos e ainda subsidiam em meu processo de trabalho atual.

\section{Considerações finais}

O presente artigo apresentou resultados de uma pesquisa acerca das relações entre a formação em um mestrado profissional em Atenção Primária à Saúde (duas turmas) e atuação profissional posterior dos egressos. Além disso, serviu para aperfeiçoar a metodologia e as estratégias de avaliação educacional desenvolvidas em estudos anteriores na instituição estudada (ENSP/Fiocruz). Sobre os resultados, pode-se dizer que a maioria dos egressos permanece atuando no âmbito do SUS, muito embora com vínculo de celetistas (e não estatutários), ou seja, continuaram atuando nos serviços ou gestão da Atenção Primária à Saúde municipal, escopo de perfil profissional quando na seleção do curso. A maioria dos profissionais exercia, ou passou a exercer durante o curso, a função de preceptoria em serviço da residência médica em Medicina de Família e Comunidade (curso ofertado pela SMSRio), a qual havia apresentado expansão vertiginosa no número de alunos no período concomitante ao Mestrado ${ }^{17}$.

De forma independente do local de atuação e a nosso ver, em um movimento virtuoso, o curso provocou mudanças na vida e no trabalho dos egressos. Os profissionais assumiram novos papéis, quer seja mantendo-se na assistência e na preceptoria - tarefas centrais para os serviços e a formação de residentes/alunos - ou incorporaram funções na gestão, ensino e pesquisa. Mostraram-se satisfeitos com a formação, seus conteúdos, metodologia e aspectos operacionais, além de apresentarem sugestões de melhoria dos componentes de avaliação formativa do curso e dos conteúdos relativos às metodologias de investigação.

Esses resultados trouxeram aos coordenadores do curso ânimo com a experiência e estimularam novos empreendimentos, como a realização da $3^{\text {a }}$ turma do curso em 2018-2020, apontando para modelos de formação que possam ser ainda mais consistentes na utilização das metodologias ativas. Corroborando reflexões sobre a concepção do curso apresentada em seu projeto pedagógico ${ }^{18}$, dentre os desafios na formação do MPAPS, destacam-se no plano epistemológico, o desenvolvimento de competências para a formação profissional que produzam sentidos coerentes com a importância da Atenção Primaria à Saúde para a consolidação do SUS e com a noção de saúde como produção social. Na perspectiva das estratégias de ensino-aprendizagem, o uso de dinâmicas que valorizam os sujeitos da aprendizagem, seus contextos socioculturais e experiências e, no que se refere aos ambientes e relações do trabalho, a efetiva problematização das mesmas, trazendo-as para o ambiente de aprendizagem. Estratégias baseadas em situações-problemas e/ ou problematização de práticas do cotidiano, grupos tutoriais, seminários, dramatizações, projetos em equipe, roda de conversas, dentre outras, foram vivenciadas (e bem avaliadas) pelo grupo.

Como limitação, pode-se citar o reduzido universo de participantes (apenas duas turmas) e o tempo de 2-4 anos de conclusão do curso, por vezes curto para se avaliar o efeito da formação na trajetória do egresso. Como componente inovador e potencialidade, destaca-se a carência de estudos como o aqui apresentado, além da metodologia do estudo, que utilizou estratégias de coleta de dados a distância, com instrumentos de autopreenchimento e anônimos, conforme já vem sendo utilizados em outros inquéritos epidemiológicos, para estudo de morbidade no Brasil. Esta metodologia mostrou-se factível, ágil e promotora de razoável adesão dos respondentes; talvez prejudicada pelo período curto de coleta (1-2 meses), quando alguns profissionais estavam de férias (julho). Inspirado no êxito desta experiência, e reforçando a relevância de se dispor de informações oportunas acerca da trajetória de egressos, seguiram-se experiências de monitoramento e avaliação dos egressos de outros cursos nos programas de nossa Escola.

Pode-se concluir pela importância e factibilidade do acompanhamento de egressos de cursos de pós-graduação, atividade que vem ganhando destaque em políticas que visem a melhoria da qualidade do ensino no país. Ainda que insipiente, houve iniciativa do governo federal em analisar dados de egressos da pós-graduação (publicação de 2017, referente ao período de 1996 a 2014) $)^{33}$, cujo foco foi a formação e atuação de mestres e doutores à luz das diretrizes propostas pelos planos nacionais de pós-graduação de 2005-2010 e 2011-2020, planos que sinalizavam a importância de se promover a formação de recursos humanos de alto nível em áreas estratégicas, como as de Ciências da Saúde. Para além de estudos e iniciativas pontuais, o desafio é o desenvolvimento de processos contínuos de avaliação, configurando-se como um sistema de acompanhamento de egressos. Lima e Andriola ${ }^{34}$, abordando 
dificuldades em instituições de ensino superior, apontam algumas destas que podem influenciar tal acompanhamento como a não padronização de pesquisas, a periodicidade de realização das mesmas; a baixa taxa de respostas; a necessidade de incentivos à estas; a qualificação de pessoal para a condução da pesquisa; o relacionamento da instituição com o egresso; integração entre diferentes sistemas institucionais para captação de dados; demora e transparência na divulgação de resultados e a integração com o mercado de trabalho. Tais considerações poderiam ser pensadas no âmbito das instituições de pós-graduação.

\section{Colaboradores}

EM Engstrom, VA Hortale e COF Moreira participaram igualmente de todas as etapas de elaboração do artigo.
Reafirma-se, pois, a importância de acompanhamento da trajetória profissional de egressos de cursos de pós-graduação; que estas avaliações contribuam para formação mais comprometidas e afinadas às diretrizes da atual política de formação para o SUS, às mudanças na legislação educacional e ao mercado de trabalho das áreas de atuação dos alunos. Isso é especialmente importante em tempos de grandes mudanças, por assim dizer, ameaçadoras ao direito à saúde, às conquistas históricas do SUS como sistema universal, público e equânime.

\section{Referências}

1. Brasil. Coordenação de Aperfeiçoamento de Pessoal do Ensino Superior. Portaria ${ }^{\circ}{ }^{80}$, de 16 de dezembro de 1998. Dispõe sobre o reconhecimento dos mestrados profissionais e dá outras providências. Diário Oficial da União 1999; 11 jan.

2. Velloso J, organizador. A Pós-Graduação no Brasil: Formação e trabalho de mestres e doutores no país. $2^{\mathrm{a}}$ ed. Brasília: Fundação Coordenação de Aperfeiçoamento de Pessoal de Nível Superior; 2005.

3. Hortale VA. Mestrado Profissionalizante em Saúde Pública: Um Olhar para as Experiências Internacionais. In: Leal MC, Freitas CM, organizadores. Cenários Possiveis: experiências e desafios do mestrado profissional na saúde coletiva. Rio de Janeiro: Fiocruz; 2006. p. 65-99.

4. Leal MC, Freitas CM, organizadores. Cenários Possíveis: experiências e desafios do mestrado profissional na saúde coletiva. 1a ed. Rio de Janeiro: Fiocruz, 2006

5. Santos GB, Hortale VA, Arouca R. Mestrado Profissional em Saúde Pública: caminhos e identidade. Rio de Janeiro: Fiocruz; 2012.

6. Brasil. Coordenação de Aperfeiçoamento de Pessoal de Nível Superior (Capes). Proposta de Aprimoramento do Modelo de Avaliação da PG Documento Final da Comissão Nacional de Acompanhamento do PNPG 2011-2020 - 10/10/2018. Brasília: CAPES; 2018.

7. Giovanella L, Mendonça MHM. Atenção Primária à Saúde. In: Giovanella L, Escorel S, Lobato LVC, Noronha JC, Carvalho AI, organizadores. Políticas e sistemas de saúde no Brasil. 2a ed. Rio de Janeiro: Fiocruz; 2012. p. 368-393.

8. Paim JS. Sistema Único de Saúde (SUS) aos 30 anos. Cien Saude Colet 2018; 23(6):1723-1728.

9. Brasil. Ministério da Saúde (MS). Política Nacional de Atenção Básica. Brasília: MS; 2017.

10. Pinto LF, Giovanella L. Do Programa à Estratégia Saúde da Família: expansão do acesso e redução das internações por condições sensíveis à atenção básica (ICSAB). Cien Saude Colet 2018; 23(6):1903-1913. 
11. Moreira COF, Dias MSA. Diretrizes Curriculares na saúde e as mudanças nos modelos de saúde e de educação. ABCS Health Sci 2015; 40(3):300-305.

12. Lima VV. Competência: distintas abordagens e implicações na formação de profissionais de saúde. Interface (Botucatu) 2005; 9(17):369-379.

13. Hortale VA, Moreira COF, Bochner R, Leal MC. Trajetória profissional de egressos de cursos de doutorado nas áreas da saúde e biociências. Rev Saude Publica 2014; 48(1):1-9.

14. Hortale VA, Leal MC, Moreira COF, Aguiar AC. Características e limites do mestrado profissional na área da Saúde: estudo com egressos da Fundação Oswaldo Cruz. Cien Saude Colet 2010; 15(4):2051-2058.

15. Harzheim E, Pinto LF, Hauser L, Soranz D. Avaliação dos usuários crianças e adultos quanto ao grau de orientação para Atenção Primária à Saúde na cidade do Rio de Janeiro, Brasil. Cien Saude Colet 2016; 21(5):1399-1408.

16. Soranz D, Pinto LF, Penna GO. Eixos e a Reforma dos Cuidados em Atenção Primária em Saúde (RCAPS) na cidade do Rio de Janeiro, Brasil. Cien Saude Colet 2016; 21(5):1327-1338.

17. Justino ALA, Oliver LL, Melo TP. Implantação do Programa de Residência em Medicina de Família e Comunidade da Secretaria Municipal de Saúde do Rio de Janeiro, Brasil. Cien Saude Colet 2016; 21(5):14711480.

18. Engstrom EM, Motta JI, Venâncio SA. A formação de profissionais na pós-graduação em saúde pública e atenção primária à saúde no município do Rio de Janeiro, Brasil. Cien Saude Colet 2016; 21(5):1461-1470.

19. Machado MFAS, Vieira NFC, Hortale VA, Vieira-Meyer APGF, Morais APP, Aguiar ASW, Gomes AMA, Silva GSN, Coimbra LC, Dias MSA, Vasconcelos MIO, Moreira COF, Tomaz JBC, Forte FDS, Monteiro CFS. O processo de construção do currículo no mestrado profissional em saúde da família. Trab. educ. saúde 2015; 13(Supl. 2):39-52.

20. Engstrom EM, Moreira COF, organizadores. Curso de Mestrado Profissional em Atenção Primária com ênfase na Estratégia Saúde da Família. Orientações para o curso. Rio de Janeiro: Brasil. Ministério da Saúde (MS), Fiocruz; 2013.

21. Flick U. Introdução à pesquisa qualitativa. $3^{\text {a }}$ ed. Porto Alegre: Artmed; 2009.

22. Rossi PH, Freeman HE. Evaluation: A Systematic Approach. Newbury Park: Sage; 1993.

23. Gomes MHA, Goldemberg P. Retrato quase sem retoques dos egressos dos programas de pós-graduação em Saúde Coletiva, 1998-2007. Cien Saude Colet 2010; 15(4):1989-2005.
24. Bourdieu P. Razões práticas: sobre a teoria da ação. Campinas: Papirus; 1996.

25. Bourdieu P. Escritos de educação. Petrópolis: Vozes; 1998.

26. Grangeiro MVT, Alencar DT, Barreto JOP. A Síndrome de Burnout: Uma Revisão da Literatura. Saúde Coletiva 2008; 2:1441-1982.

27. Trigo TR, Teng CT, Hallar JEC. Síndrome de Burnout ou estafa profissional e os transtornos psiquiátricos. Rev. Psiq. Clin. 2007; 34(5):223-233.

28. Lorenz VR, Guirandello EB. O ambiente da prática profissional e Burnout em enfermeiros na atenção básica. Rev. Latino-Am. Enfermagem 2014; 22(6):1-8.

29. Porciuncula AM. Síndrome de Burnout em gerentes da atenção primária à saúde [dissertação]. Rio de Janeiro: Fiocruz; 2015.

30. Lima AS, Farah BF, Teixeira MTB. Análise da prevalência da síndrome de burnout em profissionais da atenção primária em saúde. Trab. Educ. Saúde 2018; 16(1):283-304.

31. Mamede S, Penaforte J, organizadores. Aprendizagem Baseada em Problemas: anatomia de uma nova abordagem educacional. Fortaleza: Hucitec; 2001.

32. Lima VV. Espiral construtivista: uma metodologia ativa de ensino-aprendizagem. Interface (Botucatu) 2017; 21(61):421-434.

33. Brasil. Ministério da Educação Coordenação de Aperfeiçoamento de Pessoal de Nível Superior (CAPES). Relatório Técnico da DAV. Egressos da Pós-Graduação: Áreas Estratégicas. Brasília: CAPES; 2017.

34. Lima LA, Andriola WB. Acompanhamento de egressos: subsídios para a avaliação de Instituições de Ensino Superior (IES). Avaliação 2018; 23(1):104-125.
Artigo apresentado em 02/09/2019

Aprovado em 23/10/2019

Versão final apresentada em 25/10/2019 